\title{
Perilaku dan Pola Asuh Induk (Parental Care) Terhadap Anak Gajah Sumatera (Elephas maximus sumatranus) di Taman Margasatwa Ragunan
}

\author{
Claudya Larisha $^{1}$, Isep Herdiana ${ }^{2}$, Donny Gunaryadi ${ }^{3}$, Dewi Elfidasari ${ }^{1}$ \\ ${ }^{1}$ Program Studi Biologi, Fakultas Sains dan Teknologi, Universitas Al Azhar Indonesia, \\ ${ }^{2}$ Taman Margasatwa Ragunan, Jalan Harsono No.1, Ragunan, Ps.Minggu, Jakarta Selata \\ ${ }^{3}$ Fauna dan Flora International-Indonesia Programme
}

Penulis untuk Korespondensi/E-mail: larishaclaudya@gmail.com

\begin{abstract}
Abstrak - Gajah Sumatera (Elephas maximus sumatranus) merupakan hewan sosial yang menganut sistem matriarki. Induk akan bersikap protektif, agresif, menemani dan membantu aktivitas keseharian anak gajah seperti bermain, berkomunikasi, dan menyusui. Perilaku pengasuhan anak gajah dapat berbeda antara habitat asli dengan konservasi $e x$-situ seperti kebun binatang yang memiliki ruang gerak terbatas. Pengamatan ini bertujuan untuk menerangkan perilaku dan pola pengasuhan induk terhadap anak gajah Sumatera di konservasi $e x$ - situ. Tempat pengamatan dilakukan di Taman Margasatwa Ragunan (TMR). Objek pengamatan untuk penelitian ini adalah empat individu gajah Sumatera di Taman Margasatwa Ragunan. Metode yang digunakan adalah ad libitum sampling dan focal animal sampling. Hasil pengamatan perilaku asuh induk yang berjumlah 11 macam menunjukkan tidak ada perbedaan pada setiap induk gajah. Perilaku menyusui lebih banyak dilakukan induk daripada perilaku lainnya. Perilaku allomother pada gajah betina selain induk di TMR kurang terlihat aktif karena tida terlihat faktor yang memicu terjadinya perilaku tersebut. Variasi pola asuh induk gajah di TMR ada 10 macam dan 6 macam pola asuh gajah betina selain induk (allomother). Terjadi perilaku pola asuh abnormal dan kurangnya perkembangan sosial anak gajah terhadap gajah lain selain induk karena ruang gerak dan jumlah gajah dalam satu kandang yang terbatas di TMR.
\end{abstract}

Kata kunci - Gajah Sumatera, Elephas maximus, pola asuh, allomother, hewan sosial, matriarki

Abstract - Sumatran elephant (Elephas maximus sumatranus) is a social behaviour that have adopts matriarch system. Female elephant will be protective, helping, and always accompanying the elephant calf for activities such as playing, communicating, and berast feeding. Parental care behaviour and pattern of a Sumatran elephant in ex-situ conservation and their habitat could be different. The purpose of this observation was to describe Sumatran elephant parental care behaviour and pattern in ex-situ conservation. This observation is conduct in Ragunan Zoo and the object for this study is four Sumatran elephant. The method in this observation using ad libitum and focal animal sampling. The results showed there are no difference for parental care in Sumatran elephant and there are 11 behaviour of parental care. Allomothering in Ragunan Zoo showed less vissible because there are no factor that require helping to nurture the calf. There are 10 pattern for parental care and 6 pattern for allomotehring. There has an abnormal behaviour to the Sumatran elephant and lack of social development for the calf because of the limit space and other elephants in the enclosure.

Keywords - Sumatran elephant, Elephas maximus, parental care, allomother, social animal, matriarch 


\section{PENDAHULUAN}

$\mathrm{G}$ ajah Sumatera (Elephas maximus sumatranus) merupakan hewan sosial yang memiliki ikatan keluarga terkuat dan dapat hidup berkelompok dengan jumlah anggota antara 2-50 individu. Kelompok memiliki peranan penting dalam kelangsungan hidup gajah. Karena gajah yang terkumpul dalam kelompok tersebut dapat saling membantu untuk mencari sumber makanan, tempat beristirahat, dan berkubang (Varma et al 2012). Gajah memiliki sistem sosial matriarki, yaitu seekor gajah betina yang terlihat dominan seperti morfologi tubuhnya yang terbesar dan tertua diantara kelompoknya akan menjadi pemimpin. Karena gajah tersebut dianggap lebih dewasa dan memiliki banyak pengalaman dalam hidup dibandingkan dengan gajah betina lain dalam kelompok.

Gajah betina dapat hamil ketika mencapai umur kematangan seksual dari 9 tahun dan mengandung selama 22 bulan. Setelah melahirkan anak, induk gajah akan secara eksklusif merawat (parental care) anaknya hingga mencapai 6 bulan pertama setelah melahirkan. Setelah itu, anak gajah dapat diasuh oleh anggota betina lain (Allomother) di dalam kelompok. Perilaku pengasuhan terhadap anak gajah akan mempengaruhi pertumbuhan dan perkembangan anak gajah hingga menjelang dewasa (Joshi 2009). Karena dari pengasuhan anak juga diajarkan cara bersosialisasi dan bertahan hidup. Pola beserta perilaku pengasuhan induk (parental care) terhadap anak gajah akan membantu pembentukkan karakter anak gajah ketika dewasa. Ketika anak gajah kekurangan pengasuhan dari induk.

Anak gajah akan tumbuh besar memiliki sifat agresif dan agonistik terhadap gajah lain karena kurangnya pengalaman bersosialisasi atau tidak pernah diajarkan induk pada masa kanak-kanak (Chelluri 2009). Penelitian ini dilakukan untuk menerangkan perilaku dan pola pengasuhan induk terhadap anak gajah Sumatera yang berada di Taman Margasatwa Ragunan (TMR). Data perkembangan tingkah dapat bermanfaat untuk penentuan langkah selanjutnya yang dapat diambil untuk pelestarian gajah Sumatera yang berada di konservasi ex-situ. Hasil penelitian diharapkan dapat memberikan informasi dasar mengenai perilaku, peningkatan, usaha perawatan, pengelolaan, ruang gerak gajah dan pelestarian gajah di konservasi ex-situ di Indonesia.

\section{METODE PENELITIAN}

Pengamatan ini dilakukan di kawasan kandang gajah Sumatera dalam Taman Margasatwa Ragunan (TMR) yang berada di wilayah Jakarta Selatan. Waktu pengamatan ini dilakukan selama tiga bulan dari bulan Maret hingga Mei 2015. Pengambilan data menggunakan metode ad libitum sampling dan focal animal sampling. Pengamatan perilaku pengasuhan dilakukan selama 8 jam perhari dengan frekuensi waktu 5 menit setiap aktivitas pada satu individu (Martin \& Bateson 1993). Objek pengamatan ini adalah dua ekor induk dan dua ekor anak gajah Sumatera (Elephas maximus sumatranus). Peralatan yang digunakan selama pengamatan berlangsung adalah stopwatch, kamera digital, dan alat tulis. Ragam perilaku asuhan induk terhadap anak gajah Sumatera yang diamati terdiri dari vokalisasi $(\mathrm{V})$, mencium $(\mathrm{K})$, didekati (A), diikuti $(\mathrm{F})$, bermain $(\mathrm{P})$, grooming $(\mathrm{G})$, menyusui $(\mathrm{N})$, mengajari $(\mathrm{T})$, dan mandi $(\mathrm{B})$. Perilaku menghukum seperti memukul $(\mathrm{Pu})$, dan mengejar (Ke) (Tabel 1). Data pengamatan yang diperoleh berupa kuantitatif dan kualitatif yang diperoleh berdasarkan frekuensi persentase perilaku setiap waktu interaksi gajah betina dengan anak gajah. Data kuantitatif kemudian diolah menggunakan program Microsoft Excel 2007. Hasil tabulasi data kuantitatif disajikan menggunakan tabel dan diagram.

\section{HASIL DAN PEMBAHASAN}

Objek pengamatan pada penelitian ini terdiri dari dua ekor gajah betina dewasa, satu anak gajah betina, dan satu anak gajah jantan. Mulyani (Gambar. 1B) menempati posisi sebagai pemimpin (matriarch) karena umurnya yang tertua dan ukuran tubuhnya yang terbesar dari kedua ekor gajah betina pada kandang yang ditempati di TMR. Mulyani (27 tahun) merupakan induk yang berasal dari Way Kambas Provinsi Lampung. Gajah betina ini melahirkan anak, yaitu Lestari (3 tahun) dengan berat tubuh $100 \mathrm{~kg}$ (Gambar 1B). Agustin berumur 14 tahun (Gambar 1C) melahirkan 
anak gajah jantan bernama Pangeran (Gambar 1D) yang berusia 3 tahun dengan berat badan 80kg. Agustin tidak memiliki gading dan memiliki bekas luka berwarna putih pudar pada dahi dan kedua sisi badan. Warna kulit Agustin berwarna coklat muda. Terdapat dua kandang gajah Sumatera di Taman Margasatwa Ragunan (TMR) yang berada di sebelah barat dan timur. Kandang yang digunakan untuk pengamatan adalah kandang gajah Sumatera di sebelah barat dan terbagi lagi menjadi dua kandang besar.

Dalam kandang besar tersebut terdapat dua macam bagian yaitu kandang terbuka (open enclosure) dan kandang tertutup (night room) dan kantor perawat gajah dengan total luas $2500 \mathrm{~m}^{2}$. Total luas kandang kurang memenuhi syarat yaitu minimal luas kandang tertutup 200 $\mathrm{m}^{2}$ untuk jumlah 4 ekor gajah dan kandang terbuka minimal $2000 \mathrm{~m}^{2}$ (BIAZA 2006).

Kolam gajah yang ada di Taman Margasatwa Ragunan digunakan oleh gajah untuk mandi, berkubang saat kondisi terik matahari, minum, dan bermain. Air termasuk sebagai hal yang penting dalam kehidupan gajah. Hal ini menjadikan gajah sebagai hewan yang sangat membutuhkan air (water dependant). Dalam sehari, gajah dapat meminum air sebanyak 160 liter (Veasey 2006). Konsumsi air untuk gajah di TMR tidak terlalu sering dilakukan kontrol kualitas dan kuantitasnya. Hal tersebut tidak berpengaruh pada aktivitas keseharian gajah karena perilaku minum di air kolam sama dengan perilakunya di habitat asli. Kolam gajah di TMR selalu diganti dengan air baru setiap seminggu sekali agar kotoran dan bakteri yang ada di air kolam keluar melalui saluran pembuangan. Upaya tersebut dilakukan sebagai salah satu cara meningkatkan kualitas hidup gajah agar bertahan lebih lama dibandingkan dengan gajah di habitat asli.

Perilaku parental care di TMR terdiri dari vokalisasi, mencium, mendekat, diikuti, bermain, grooming, menyusui, mandi, dan belajar. Perilaku agonistik seperti memukul dan mengejar adalah perilaku yang diamati (Joshi 2009) Persentase perilaku parental care pada penelitian ini menunjukkan tidak adanya perbedaan antara pengasuhan anak gajah jantan dan betina. Persentase perilaku asuh yang dihabiskan untuk menyusui anak gajah sebesar $41 \%$ (Gambar 4).

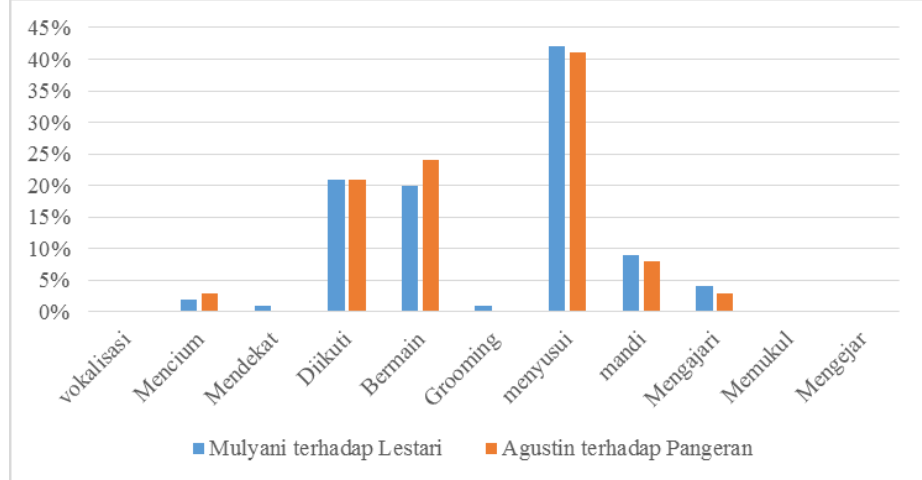

Gambar 1. Persentase Perilaku asuh induk terhadap anak gajah di Taman Margasatwa Ragunan.

Anak gajah akan meliliti puting induk dan menariknya agar susu keluar. Setelah itu, kepala anak akan dimiringkan dan puting akan dihisap dengan mulutnya. Perilaku menyusui induk terhadap anak dapat terjadi setiap waktu ketika anak gajah lapar. Perawat gajah di TMR akan memberikan tambahan nutrisi kepada anak gajah selain ASI dari induknya. Tambahan nutrisi tersebut berupa larutan air gula jawa sebanyak 1 liter sehari yang berguna untuk memberikan asupan karbohidrat tambahan sebagai sumber energi kepada anak gajah sehingga dapat tumbuh dan berkembang dengan baik (Aryanti et al 2013).

Nilai persentase perilaku bermain Pangeran dengan induknya (Agustin) sebesar 24\% (Gambar 4). Tingginya nilai persentase tersebut dapat disebabkan oleh sifat pangeran yang lebih aktif dari Lestari dan sebagai salah satu cara untuk menarik perhatian induk. Perilaku bermain Lestari dengan induknya (Mulyani) memiliki nilai persentase yang lebih rendah dari Pangeran yaitu 20\% (Gambar 4). Perilaku mandi yang dilakukan pada saat kondisi cuaca 
panas oleh kedua induk dengan anak memiliki nilai yang sama tinggi yaitu $8 \%$ (Gambar 4) dari aktivitas asuhan harian. Perilaku agonistik yang bersifat menyakiti anak gajah dapat terjadi jika emosi induk yang tidak seimbang karena stress yang disebabkan oleh lingkungan sekitar seperti ada persaingan, perkelahian dalam kelompok sendiri, ancaman predator, kekurangan makanan dan sumber air (Pinter 2008).

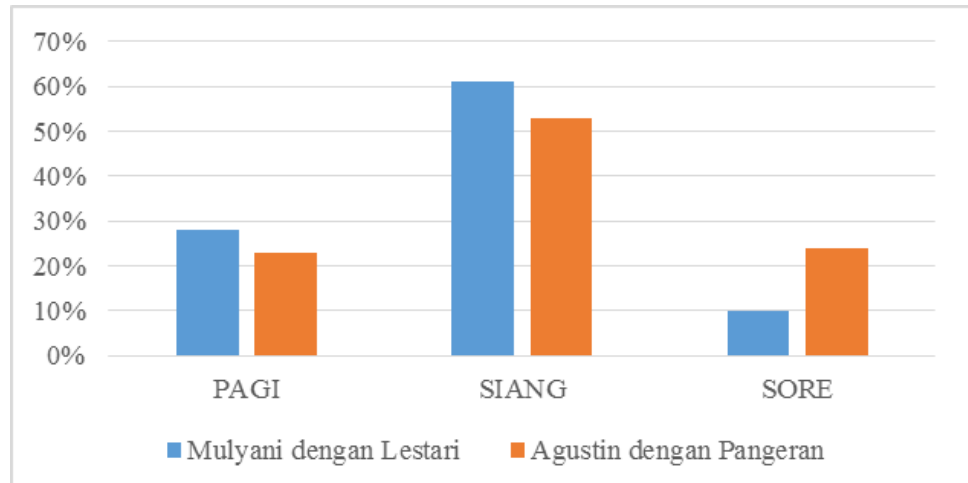

Gambar 2. Persentase perilaku asuh induk terhadap anak gajah Sumatera di Taman Margasatwa Ragunan berdasarkan tiga pembagian waktu.

Perilaku tersebut belum terjadi selama pengamatan berlangsung di TMR. Hal ini menunjukkan bahwa kondisi di TMR mendukung bagi konservasi gajah serta perencanaan penambahan populasi gajah. Kondisi lingkungan sekitar yang baik mempengaruhi induk gajah saat melahirkan dan membesarkan anak dengan tingkat emosi yang stabil. Perilaku asuh paling aktif pada kedua induk gajah Sumatera terlihat di siang hari, Mulyani sebesar 61\% dan Agustin 53\% (Gambar 6). Hal tersebut berbeda dengan gajah di habitat asli yang lebih aktif pada malam hari.
Karena gajah di konservasi ex-situ seperti taman margasatwa terbiasa dilatih oleh perawat gajah untuk aktif dari pagi hingga sore hari dan menggunakan waktu malam hari untuk istirahat agar pengunjung dapat melihat dan mempelajari perilaku aktivitas harian gajah tanpa harus menunggu sampai malam hari. Beberapa faktor dapat menyebabkan perilaku abnormalitas dapat disebabkan karena tidak ada pemicu (stressor) seperti predator yang dapat mengancam keselamatan gajah dan kelompoknya, dan persaingan antar kelompok dalam konservasi ex-situ tersebut (Veasey 2006).

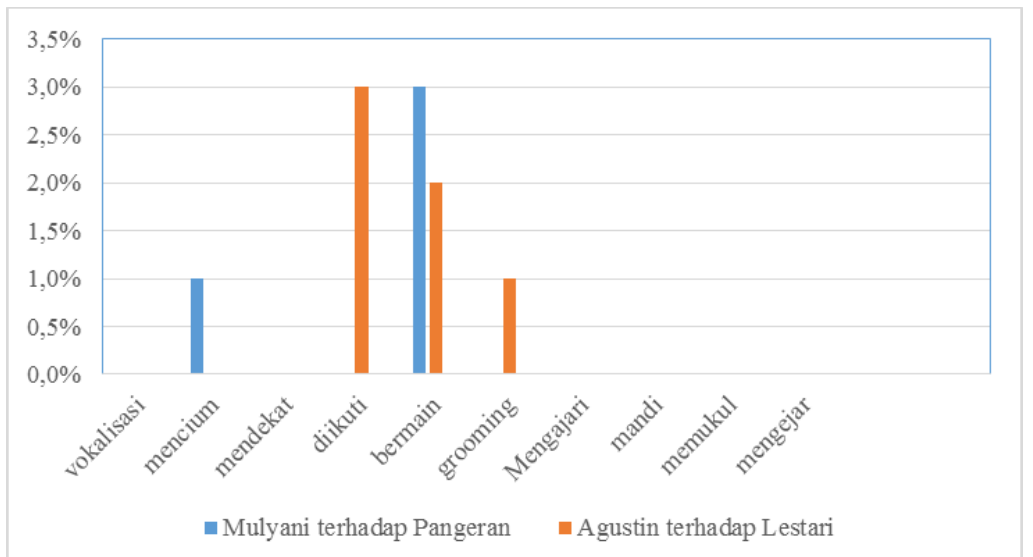

Gambar 3. Persentase perilaku asuh allomother di Taman Margasatwa Ragunan

Konservasi ex-situ seperti TMR mencegah konfrontasi antar gajah dengan tidak menempatkan gajah dengan sifat yang agresif atau jumlah yang terlalu banyak dalam satu kandang. Perilaku asuh gajah betina selain induk terhadap anak gajah lebih banyak menunjukkan perilaku bermain (Gambar 7).
Gajah betina yang mengajak bermain anak ditunjukkan dengan melilitkan belalai ke kaki depan, saling menarik ekor dengan belalai, dan saling menabrakkan badan. Perilaku grooming juga terlihat pada Agustin terhadap Lestari dengan nilai $1 \%$ dari aktivitas keseluruhan (Gambar 7). 
Perilaku tersebut dilakukan ketika Agustin mengusapkan belalai ke seluruh tubuh Lestari untuk menyingkirkan tanah atau debu. Pangeran memiliki nilai persentase mencium gajah betina lebih banyak yaitu $1 \%$ (Gambar 7) sebagai salah satu cara untuk menarik perhatian gajah betina (Joshi 2009). Variasi pola asuh induk gajah betina sumatera di TMR yang terbentuk sebanyak 10 macam semuanya terdiri dari anak gajah yang akan mengikuti terus pergerakan induk. Selain itu, dari pola tersebut sebagian besar terdiri dari perilaku pemberian ASI kepada anak gajah (Tabel 3). Perbedaan pola asuh setiap gajah sumatera betina di TMR dapat dipengaruhi oleh umur induk, jenis kelamin anak, serta karakter dari individu gajah. Variasi pola asuh pada gajah sumatera betina dapat mempengaruhi pembentukan karakterisasi anak yang akan beranjak dewasa.

Tabel 1. Pola perilaku asuh anak yang dilakukan induk gajah Sumatera di Taman Margasatwa Ragunan

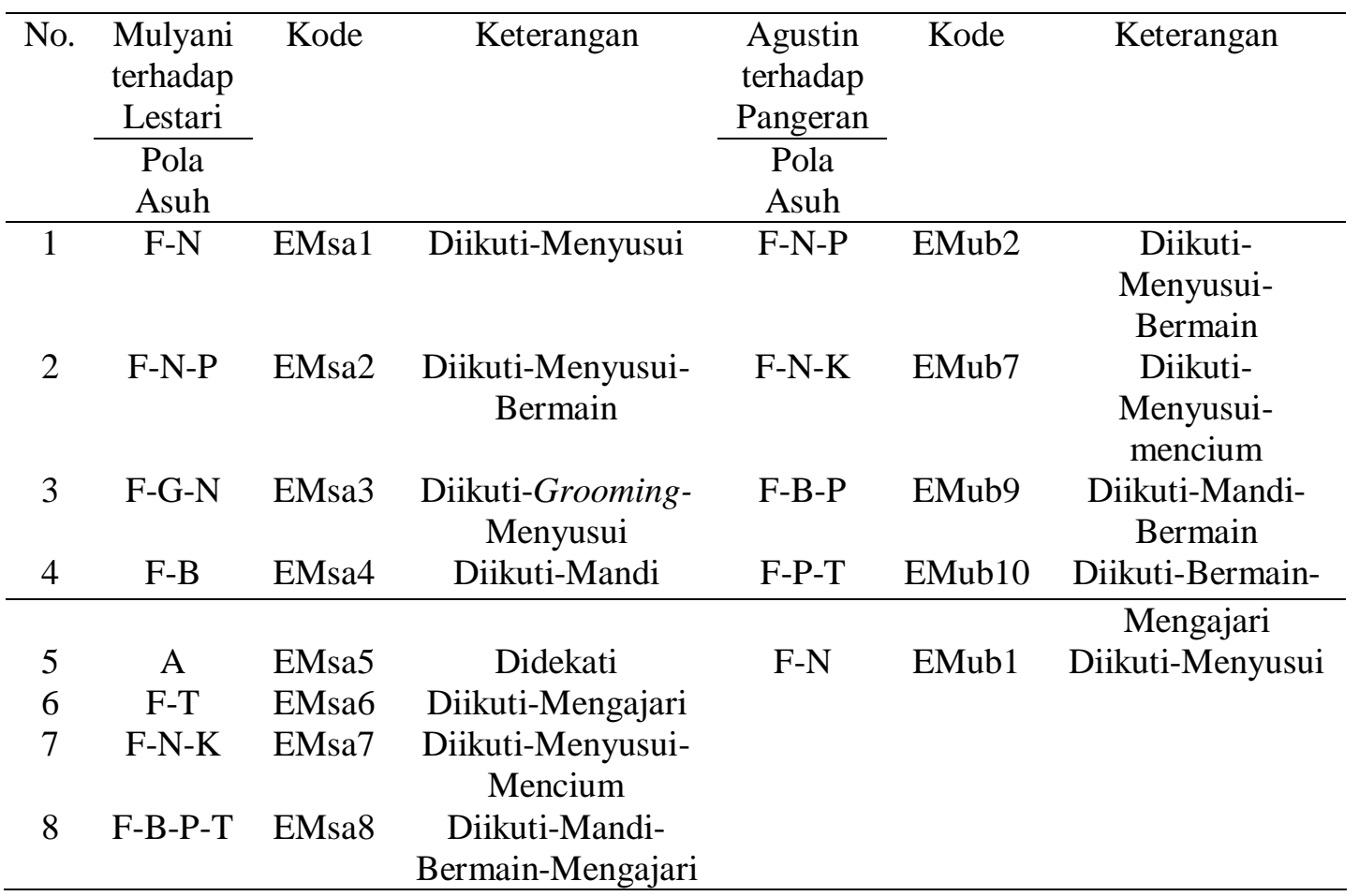

Pengaruh pengasuhan dalam pembentukan karakterisasi dilakukan ketika gajah masih berada dalam tahap anak-anak karena pada saat itu anak gajah masih menyerap segala perilaku induk dan gajah lain dalam kelompok untuk belajar bertahan hidup (Varma 2012). Berdasarkan hasil dari pengamatan yang dilakukan, variasi pola asuh gajah Sumatera di TMR dengan nilai frekuensi tertinggi sebanyak 201 kali adalah pola EMub2 (Gambar 9). Pola
EMub2 yaitu ketika anak gajah mengikuti induk lalu induk menyusui dan bermain dengan anak (F-N-P). Selain itu, pola yang sering terlihat adalah pola EMsa7 yaitu saat anak mengikuti induk lalu disusui dan mencium induk (F-N-K) dengan nilai frekuensi 115 kali (Gambar 9). Nilai terendah sebesar 4 kali (Gambar 9) dari pola pengasuhan adalah EMsa5 yaitu ketika anak mencari perlindungan dengan cara mendekat kepada induk (A). 


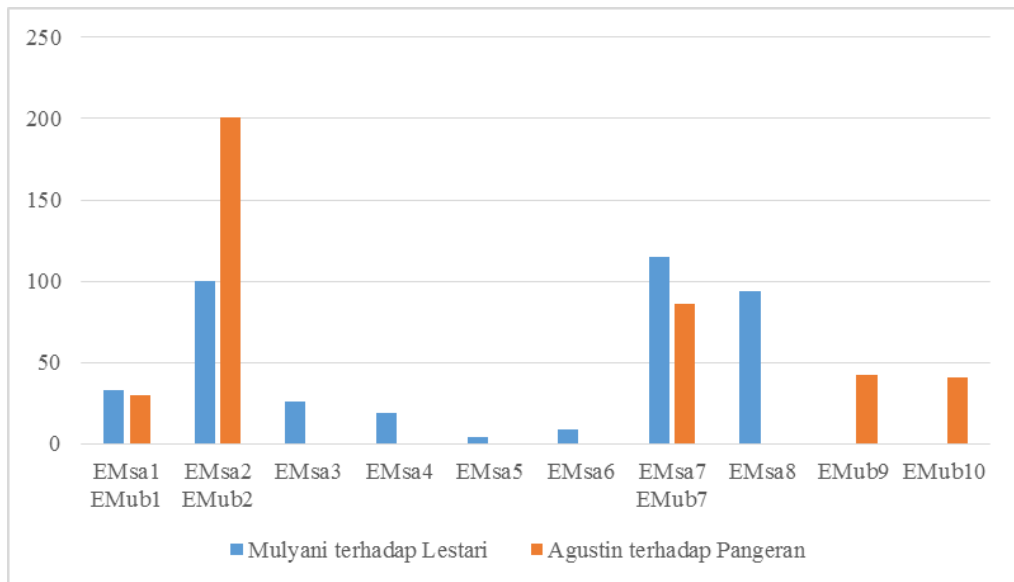

Gambar 4. Frekuensi pola asuh induk gajah Sumatera di Taman Margasatwa Ragunan

asuh allomother atau pengasuhan dari gajah betina bukan induk yaitu dari Mulyani terhadap Pangeran (EMsal) dan Agustin terhadap Lestari (EMubl) memiliki 6 macam variasi. sebagian besar terdiri dari perilaku anak gajah mengikuti dan bermain dengan gajah betina (Tabel 4). Berdasarkan frekuensi pola asuh allomother terhadap anak gajah yang tertinggi adalah pola EMubl15 (Tabel 4) dengan nilai 17 kali (Gambar 11). Pola EMubl15 (F-P-G) adalah aktivitas harian dari gajah betina yang diikuti anak lalu diajak bermain sambil mengusap-usap belalai induk ke seluruh tubuh antara gajah betina dengan anak gajah (grooming).

Tabel 2. Pola asuh allomother terhadap anak gajah Sumatera di Taman Margasatwa Ragunan

\begin{tabular}{ccccccc}
\hline No & $\begin{array}{c}\text { Mulyani } \\
\text { terhadap } \\
\text { Pangeran }\end{array}$ & Kode & Keterangan & $\begin{array}{c}\text { Agustin } \\
\text { terhadap } \\
\text { Lestari }\end{array}$ & Kode & Keterangan \\
\cline { 2 - 5 } & $\begin{array}{c}\text { Pola } \\
\text { Allomother }\end{array}$ & & & $\begin{array}{c}\text { Pola } \\
\text { Allomother }\end{array}$ & \\
\hline 1 & P-G & EMsal11 & $\begin{array}{c}\text { Bermain- } \\
\text { Grooming }\end{array}$ & F-P & EMub14 & $\begin{array}{c}\text { Diikuti- } \\
\text { Bermain }\end{array}$ \\
2 & P-K-G & EMsal12 & $\begin{array}{c}\text { Bermain- } \\
\text { Mencium- } \\
\text { Grooming }\end{array}$ & F-P-G & EMub15 & Diikuti- \\
Bermain- \\
Groming
\end{tabular}

Agustin yang terlihat lebih aktif dalam mengajak bermain Lestari ataupun terkadang juga bersama dengan Pangeran dapat disebabkan oleh faktor umur yang masih lebih muda dari Mulyani. Walaupun Agustin juga memiliki anak, selain untuk mempererat ikatan keluarga pada Lestari, Induk dari Pangeran ini juga tetap mencari dan menambah pengalaman untuk menjaga seekor anak gajah. kedua anak gajah tersebut bermain dengan Mulyani dan Agustin juga dapat membantu meningkatkan kemampuan bersosialisasi dengan baik antara Pangeran dan Lestari. Gajah adalah hewan sosial, komunikasi dan bersosialisasi sangat penting dalam kehidupan gajah untuk bertahan hidup. Gajah dapat mengenali anggota kelompok, mencari daerah makan, mempererat ikatan keluarga antar gajah dalam satu kelompok atau menghindari stress dengan melakukan komunikasi. 


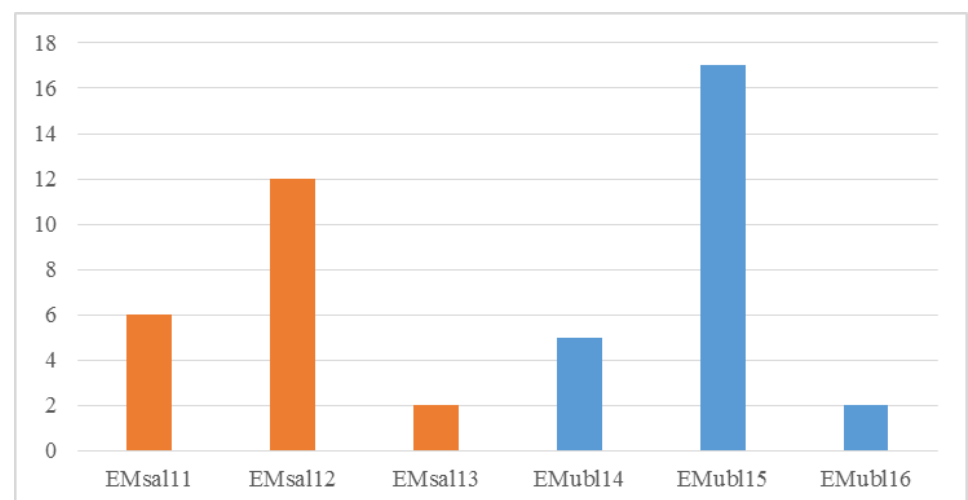

Gambar 5. Frekuensi pola asuh gajah Sumatera betina selain induk (allomother) di Taman Margasatwa Ragunan

Beberapa cara komunikasi seperti vokalisasi, sentuhan, penglihatan dan gerakan. Kandang gajah yang baik dalam suatu konservasi $e x$-situ harus menampung beberapa gajah yang berada dalam satu kelompok agar dapat tetap saling berkomunikasi dan bersosialisasi. Gajah tidak diperbolehkan hanya sendiri dalam satu kandang dengan jangka waktu yang lama. Karena, gajah yang tidak dapat berkomunikasi dengan gajah lain akan menimbulkan stress dan dapat menyebabkan kematian yang cepat bagi gajah tersebut (BIAZA, 2006). Pola asuh EMubl15 (Tabel 4) yang dilakukan oleh Agustin terlihat lebih aktif dibandingkan Mulyani yang menerapkan pola pengasuhan gajah betina EMsal12 (Tabel 4) terhadap Lestari.

Hal ini dapat menandakan bahwa perbedaan umur dan sifat karakter yang dimiliki oleh setiap individu gajah juga mempengaruhi pembentukan pola asuh terhadap anak gajah. Salah satu contohnya seperti sifat Pangeran yaitu anak gajah sumatera berjenis kelamin jantan yang lebih aktif dalam mengajak aktivitas bermain induk yang terbentuk menjadi pola asuh. Pola yang telihat dari interaksi Pangeran dengan induknya adalah EMub2, EMub9, dan EMub10. Tetapi walaupun memiliki pola asuh yang berbeda, tidak terjadi penolakan saat Mulyani diajak main dengan Pangeran ataupun saat tubuh Lestari diusap-usap dengan belalai Agustin yang menandakan bahwa anak gajah sudah mengenali gajah betina tersebut sebagai keluarganya dan terjalin ikatan kekeluargaan yang erat.

\section{KESIMPULAN}

Perilaku asuh induk gajah Sumatera (Mulyani dan Agustin) terhadap anak (Lestari dan Pangeran) di TMR menunjukkan tidak ada perbedaan. Perilaku dominan yang terlihat adalah induk menyusui anak, induk bermain dengan anak, dan anak mengikuti induk gajah sepanjang hari. Perilaku asuh allomother kurang terlihat aktif karena tidak ada faktor yang mengharuskan pengasuhan dari gajah betina lain terhadap anak gajah. Variasi pola asuh induk gajah betina di TMR ada 10 macam dan 6 macam pola asuh allomother. Perilaku vokalisasi antara induk dengan anak gajah tidak terlihat selama pengamatan. Terjadi perilaku dan pola asuh abnormal seperti aktivitas keseharian gajah yang banyak dilakukan dari pagi hingga siang hari karena perawat yang melatih agar pengunjung dapat melihat aktivitas alami harian gajah. Ruang gerak yang terbatas di kandang gajah Sumatera TMR kurang mendukung perkembangan sosial antara gajah dewasa selain induk terhadap anak karena wilayah dan jumlah individu gajah yang terbatas.

\section{UCAPAN TERIMAKASIH}

Terima kasih kepada Taman Margasatwa Ragunan karena telah berbaik hati untuk mengijinkan peneliti melakukan pengamatan mengenai perilaku gajah Sumatera dari awal hingga akhir pengamatan. Ucapan terima kasih juga disampaikan untuk para perawat satwa yang ada di kawasan Gajah Sumatera karena telah sangat banyak membantu selama pengamatan berlangsung. 


\section{DAFTAR PUSTAKA}

[1] Altmann J. 1973. Observational Study of Behaviour: Sampling Methods. Chicago: University of Chicago.

[2] Aryanti F. 2013. Pengaruh Pemberian Air Gula Merah terhadap Performans Ayam Kampung Pedaging. Jurnal Sain Veteriner 31(2): 156-165.

[3] [BIAZA] British and Irish Association of Zoos and Aquariums, 2006. Management Guidelines for the Welfare of Zoos Animals: Elephants. London (UK): British and Irish Association of Zoos and Aquariums.

[4] Chelluri G. 2009. Ontogeny of The Mother-calf Relationship in African Forest Elephants (Loxodonta africana cyclotis) [Thesis]. Biological Sciences Ecology and Evolutionary Biology.

[5] Joshi R. 2009. Asian Elephant's (Elephas maximus) Behaviour in the Rajaji National Park, North-West India :
Eight Years with Asian Elephant. Nature and Science 7(1): 49-77.

[6] Martin P, Bateson P. 1993. Measuring Behaviour: An Introductory Guide Second Edition. United Kingdom: Cambridge University Press.

[7] Meytasari P. 2014. Penyusunan Kriteria Domestikasi dan Evaluasi Praktek Pengasuhan Gajah: Studi di Taman Nasional Way Kambas Kabupaten Lampung Timur. Jurnal Sylva Lestari, 2(2): 79-88.

[8] Varma S, Baskaran N, Sukumar R. 2012. Field Key for Elephant Population Estimation and Age and Sex Classification Field Key for Elephant Population Estimation and Age and Sex Classification. karnataka: Indian Institute of Bangalore.

[9] Veasey J. 2006. Concepts in The Care and Welfare of Captive Elephants. International Zoo Yearbook (40): 6379. 